\title{
Towards a new ophthalmic biology and physiology: the unsuspected intrinsic property of melanin to dissociate the water molecule
}

\begin{abstract}
The development and evolution of eyes is ancient and difficult problem in biology. Darwin postulated a prototype eye which can evolve under natural selection. NeoDarwinists, based in morphological criteria, have postulated a polyphyletic origin that has evolved independently in the various animal phyla. Molecular phylogenetic analyses and developmental genetic experiments, cast serious doubts on both theories. The study of the development of the eye in the amphibian embryo has been a formidable tool research to experimental embryology and evolutionary biology as early as 1901. The embryonic induction, the interactions between different embryonic tissues (organizers); and the role of genes, were conceived as result of reciprocal transplantation experiments.
\end{abstract}

The classical description is that the eye in vertebrates develops from the neural plate, as an evagination from the brain, forming the optic vesicle; which subsequently invaginates to form the optic cup. The inner layer of the optic cup forms the retina with its photoreceptor layers, whereas the outer layer gives rise to the pigment epithelium which absorbs the light in the back of the retina. However, failed to recognize the importance of melanin pigment. The mammalian eye consists of several layers that contain melanin, $40 \%$ more than skin in average. Retinal, Iris and ciliary pigment epithelial cells are derived from neural ectoderm, oppositely, the uveal melanocytes, placed in choroid, iris and ciliary body stroma, are developed from the neural crest. The photo screening protective effects of melanin, the biophysical and biochemical also protective effects and biologic and photo biologic effects; have been extensively studied, but so far, researchers have been considered melanin merely as a sun block with difficult-to-explain properties. Therefore, the unsuspected intrinsic property of melanin to transforms visible and invisible light, into chemical energy, through water dissociation, as chlorophyll in plants, founded in our research facility in 2002 break the ground in regards our concepts about the biology and physiology of the body and therefore the eye. Melanin is a fundamental molecule in bioenergetic pathways, wherever is placed, and the ocular globe is not an exception. Thereby, the main function of melanin in the eye, is chemical energy production through water dissociation, as chlorophyll in plants.

Keywords: melanin, melanosomes, energy, light, water dissociation, hydrogen, oxygen
Volume 4 Issue 2 - 2017

\begin{abstract}
Arturo Solis Herrera
Director, Human Photosynthesis $®$ Research Center, México
\end{abstract}

Correspondence: Arturo Solis Herrera, Director, Human Photosynthesis $₫$ Research Center, México,

Email comagua2000@yahoo.com

Received: March 07, 2017 | Published: April 27, 2017

\section{Introduction}

Charles Darwin (1809-1882) confessed that it is an absurd idea that vertebrate eye could be evolved through natural selection. ${ }^{1}$ Darwin's eye definition was as an organ consisting of at least two different cell types: photoreceptor and pigment cells; this is the Darwinian prototype. Early organisms, more than 600million years ago, (Mya), evolved primitive photoreceptors capable of signaling light. During the Cambrian explosion (540 Mya), animal body evolving rapidly. ${ }^{2}$ "The simplest organ which can be called an eye consists of an optic nerve, surrounded by pigment cells and covered by translucent skin, but without any lens or other refractive body" Thereby, since Darwin's time, the ever presence of melanin was detected. Planarian species in Japan (Polycelis auricularia) has multiple eyes with one photoreceptor cell and one pigment cell only. The general vertebrate plan of an eye-ball encased in three coats: sclera, choroid, and retina, forming a dark chamber filled with clear fluids under pressure. The cornea, a transparent tissue of varying refractive power, depending of habitat. Within the eye is a lens whose means of accommodation is variable in terms of evolution. The lens is pliable and transparent. Accommodation is obtained by striated ciliary muscles cantilevering from a ring of scleral ossicles to deform the lens, rather by to-and-fro movement as it is in fishes. For binocular vision, there is assistance in convergence by a transversal is muscle which orients the lens nasally. The mechanisms for both accommodation and convergence are newly evolved for reptiles. In biology, nothing makes sense except in light of evolution, resolving eye diseases that afflict the population, therefore, requires that we understand the embryology of the organ itself. If we can understand as are originate the tissues, also can understand how they work, and therefore the mechanisms of health and disease.

\section{Background}

Decades ago exists the belief that the opsins are the molecules in 
where is starts the phenomenon of the vision. But the conformational change cis-trans is relatively weak process that cannot explain the diverse and highly complex biochemical events which are observed during the transduction of light to bio-electrical energy. Rhodopsin is a molecule of extreme sensitivity, since it allows (apparently) the detection of a single quantum of light; and by amplification of this signal, it can trigger a nerve impulse. However, amplification means energy expenditure, and the triggering of a nerve impulse also involves available chemical energy so the biochemical reactions involved, can be impelled. By other hand, rhodopsin is subject to strong functional evolutionary constrains, not so the melanin molecule. The finding that the genetic code is conserved from $E$. coli to humans indicates that all the known organisms on earth go back to a common ancestor, ${ }^{3}$ but in our experience the so much-looked common ancestor is, precisely melanin molecule due to it is the missing link between energy and cell, and not precisely some kind of ancient organism.

True visual pigment is melanin, and not the rhodopsin. So is so, we don't find eyes of any type, already is in vertebrates (ciliary photoreceptors cells), cephalopods (rhabdomeric photoreceptors), insects or ark clams (compound eyes) in that not is present the melanin, not so the rhodopsin. Therefore, rhodopsin is part of the metabolic visual pathway that starts in melanin, or more strictly in the energy that melanin provides in form of molecular hydrogen $\left(\mathrm{H}_{2}\right)$ and high energy electrons (e-). Which tells us that the truly important element in the equation of the development and evolution of the eye is neither more nor less than the melanin molecule, due to its intrinsic property to transform visible and invisible light, into chemical energy through water dissociation, as chlorophyll in plants? The universality of Pax 6 control in eye development means that gene regulatory sequences (enhancers and silencers) are also highly conserved in evolution. Pax specific enhancer $\left(\mathrm{P}_{3}\right)$, i.e., is found in front of the rhodopsin ranging from fruit flies to humans, ${ }^{4}$ because the development of Pax specific enhancer happened always behind melanin energy production.

It is remarkable that melanin is the same molecule since the beginning of time, can be said that it has not had to evolve, as their function has been and is always the same: production of chemical energy through the dissociation of the molecule of water, such as chlorophyll in plants. But what really shows evolutionary changes are the other components of the eye, starting with genes, passing by the refractive and structural elements which seem to evolve from requirements imposed by the environment in different ways of life. But the chemical energy that emanates from the melanin, in the form of molecular hydrogen $\left(\mathrm{H}_{2}\right)$ and high energy electrons (e-), it is shaped so constant, so accurate, going on both night and day (Table 1); that fully explains cell energy requirements no doubt are needed by evolutionary and vital processes. Hence the omnipresence of melanin in the biology and physiology of the eye. As the kind of energy that drove the first reaction of life, as well as the growing complexity of evolutionary processes, physical-chemical properties of Melanin remains unchanged. It has not moved in the slightest, as does not, cannot, and not has to do it. They have always been and will be the hydrogen molecular $\left(\mathrm{H}_{2}\right)$ and electrons of high energy (e-), which come from dissociation and back-bonding of the water molecule. The evolution can be defined as the gradual optimization of the chemical energy from of the melanin, what allows, with the same energy, boost processes each time more complex and simultaneously and therefore, more efficiently used.

In other words, the generation of energy from melanin remains unchanged over time, what it evolves, it is the scaffolding or gear around the melanin molecule that nature has been generated over millions of years of evolution, this is: energy distribution. Energy generation by melanin is the same process from the beginning of times, there is no change about it. The growing complexity of energy distribution in order to get maximal worth is what we call evolution. Limited conformational changes that we observe in the rhodopsin molecule, do not depend on the light itself, but rather depend on power that melanin releases, in form of $\mathrm{H}_{2}$ and e-, due to its unexpected ability to dissipate the notably amount of energy that melanin can absorbs from the full electromagnetic spectrum, through the dissociation of the water molecule. It is believed that optic cup in vertebrates gives rise to both retinal photoreceptor cells and retinal pigment cells support a common evolutionary origin, but at light of intrinsic capacity of melanin to dissociate the water molecule, seems more congruous that melanin gives origin to the optic cup. Because of their unexpected ability to generate chemical energy, which is required for the highly-ordered sequence of biochemical events, must occur in a long-last reliable form. Thereby, in regards the origin of life, melanin was first and life after.

Table I Comparative table between the activity of the heme group of the chlorophyll and the melanin.

\section{Chlorophyll:}

$$
\begin{aligned}
& 2 \mathrm{H}_{2} \mathrm{O}_{\text {(Liquid) }} \rightarrow 2 \mathrm{H}_{2} \text { (gas) } \\
& \text { Melanin } \\
& 2 \mathrm{O}_{2} \text { (gas) } \mathrm{O}_{\text {(Liquid) }} \leftrightarrow 2 \mathrm{H}_{2} \text { (gas) } \\
&
\end{aligned}
$$

Compounds possessing the heme group such as chlorophyll, hemoglobin the bilirubin, and cytochrome $\mathrm{P}-450$, are capable of dissociating water in an irreversible manner, while melanin can disassociate it (gas) and return it to liquid form.

\section{Melanosomes}

Melanosomes are organelles responsible for the synthesis of the major mammalian pigment melanin ${ }^{5}$ and melanophores in lower species. Defects in melanin synthesis and storage result in reduced pigmentation of skin, hair and eyes; leading to decreased protection against ultraviolet radiation, visual deficits, neurodegenerative disorders, and increased susceptibility to skin and eye cancers. In the eye, the uveal tract is a highly vascularized and pigmented tissue (Figure 1). Anatomically is divided in Iris, ciliary body and the choroid. The choroid supports and nourishes the retina, which is located on the inner side of the choroid. Between both layers, uveal tract and the neural retina we have the retinal pigment epithelium (RPE), a monolayer derived from neuroectoderm, that is responsible for important metabolic support for the entire retina and is involved in phagocytosis of the photoreceptor outer segments disks, which are constantly being shed, ${ }^{6}$ at approximately rate of one membranous disc per hour. Melanocytes of choroid and iris (Uvea, from Greek: grape color) immigrate from the neural crest. ${ }^{7}$ While the turnover of melanin is high in the skin, ${ }^{8}$ the amount of melanin turnover in the eyes of adult vertebrates is completely unknown, in spite melanin in the eyes is exposed to an environment that generates $\mathrm{H}_{2} \mathrm{O}_{2},{ }^{9}$ and free radicals which can interact with melanin. ${ }^{10}$ Melanin metabolism in the RPE of 
adult vertebrates is poorly understood. The RPE is highly specialized to degrade the shedder tips of the rod outer segments. ${ }^{11}$ One RPE cell must continuously engulf some $300,000,0000$ disc during a 70 -year life span. ${ }^{12}$ The fate of degradation products and whether or how they cross the Bruch membrane is still unknown. ${ }^{13}$

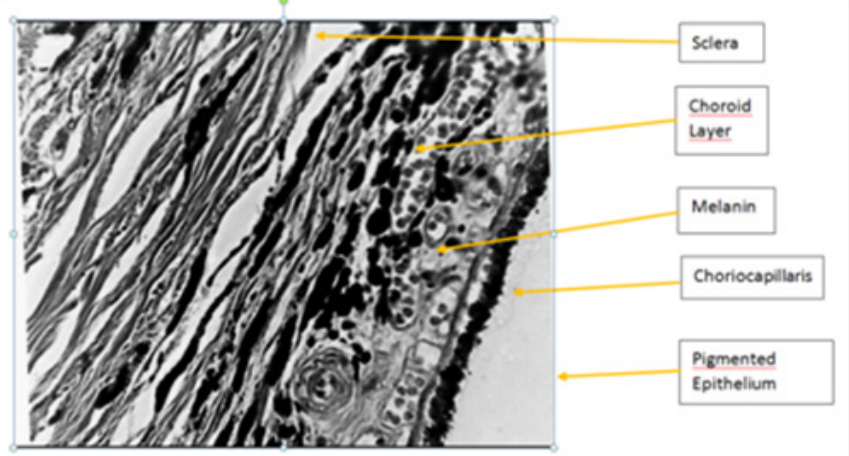

Figure I Microphotography shows main components of uveal tract.

Whereas the turnover of photoreceptor membrane is very high, the turnover of melanin is believed to be absent in the RPE of adult mammals ${ }^{14}$ or at least restricted to the prenatal period. ${ }^{15}$ By other hand, melanin is the most stable substance man ever known, 160million years demonstrated. ${ }^{16}$ Although it is well known that excessive sunlight can destroy melanin in human skin, destruction of melanin by light is believed to be absent in the RPE. Melanogenesis in the RPE was observed only under experimental conditions as intense bright light exposure, or injection of autologous vitreous in the subretinal space. ${ }^{17}$ There are very interesting observations have neither been understood nor investigated in detail. Association of lysosomes and melanosomes is particularly prominent in disease like the ChediakHigashi syndrome or retinitis pigmentosa. ${ }^{18}$ The association between melanosomes and lysosomes, which also occur independent of diseases, is so consistent that led to the term melanolysosome. It is of interest, that ocular melanin strongly binds chloroquine, which is normally accumulated in lysosomes.

Melanosome-laden macrophages were found in different vertebrate species independent of pathological conditions. In teleost retina, melanin-laden phagocytes are a constant feature and extremely numerous. These wandering phagocytes are also observed in mammalian RPE of ferret. In hamsters kept under normal light conditions in the laboratory, the melanocytes of the choroid appear metabolically inactive as judged by the poor development of cytoplasmic organelles, however, after intense illumination for 12 hour and an additional stay in the dark, melanocytes of the choroid can be activated. ${ }^{19}$ It has been speculated that iridial and choroidal melanocytes are essentially the same cell types that have same developmental history and differ only in the timing of their maturation and terminal differentiation. ${ }^{20}$ It is believed that the melanocytes of the iris synthesize melanin throughout adult life. Iris uveal melanocytes differ from those of the choroid in the fine structure of their melanosomes. There is a hypothesis that the major protecting effect of ocular melanin should result from its metal ion binding capacity. Furthermore, phagocytosis processes are associated with the generation of radicals, and RPE is highly active in phagocytosis.

\section{Melanin}

Physical-chemical complexities enable melanin to perform many roles. Melanin stand out in hair, hair follicles, skin (epidermis, dermis), eyes (uveal tract, conjunctiva), Central nervous system (substantia nigra, locus coeruleus, leptomeninges, choroidal plexuses, etc.), inner ear (stria vascularis), reproductive organs, gastrointestinal tract, feathers, scales; etc. Every body's cell contain genetic information to synthesize melanin. Melanin is involved in animal reproductive and social behavior, absorbs UV rays, may prevent and promote skin melanoma, scavenges toxic free-radicals and absorbs heavy metal cations; in the brain, melanin function has been confused, inhabit leptomeninges, surfaces of the medulla oblongata; cerebral hemisphere; around median eminence (in rats); about blood vessels in the mammalian cochlea, and dendritic melanocytes containing melanosomes are in contact with frog Leydig cells. Melanin is also described in wandering cells as macrophages.

It is speculated that melanocytes exposed or not to visible light, may differ in function. Melanocytes proximity to blood vessels in some internal locations suggests endocrine function. ${ }^{21}$ Prostaglandin D synthetase is expressed in melanocytes but not in other skin cell types. It is interesting that chemical-physical qualities of natural aggregates of melanin monomers are still undefined. Origin of absorption by melanin across the full UV visible band and beyond remains controversial. Activity of natural melanins may be less complex to fathom than structure and physical-chemical properties. ${ }^{22}$ Melanin also has been reported that reduces DNA damage, respiration down $30 \%$, and mitochondria number are significantly different in fair skin than in dark skin, until an $83 \%$ less in dark skin. The melanin is the pigment more diffused in the nature. We can find it on the ground, the trunk of trees, insects, mammals; etc. (Figures 2-5) Its importance lies in that is the transducer by excellence that allow capture the energy of the light, transforming it in chemical energy through the dissociation of the water, as the chlorophyll in plants. It is no coincidence that melanin is in the eyes of vertebrates and invertebrates. Even since its formation.

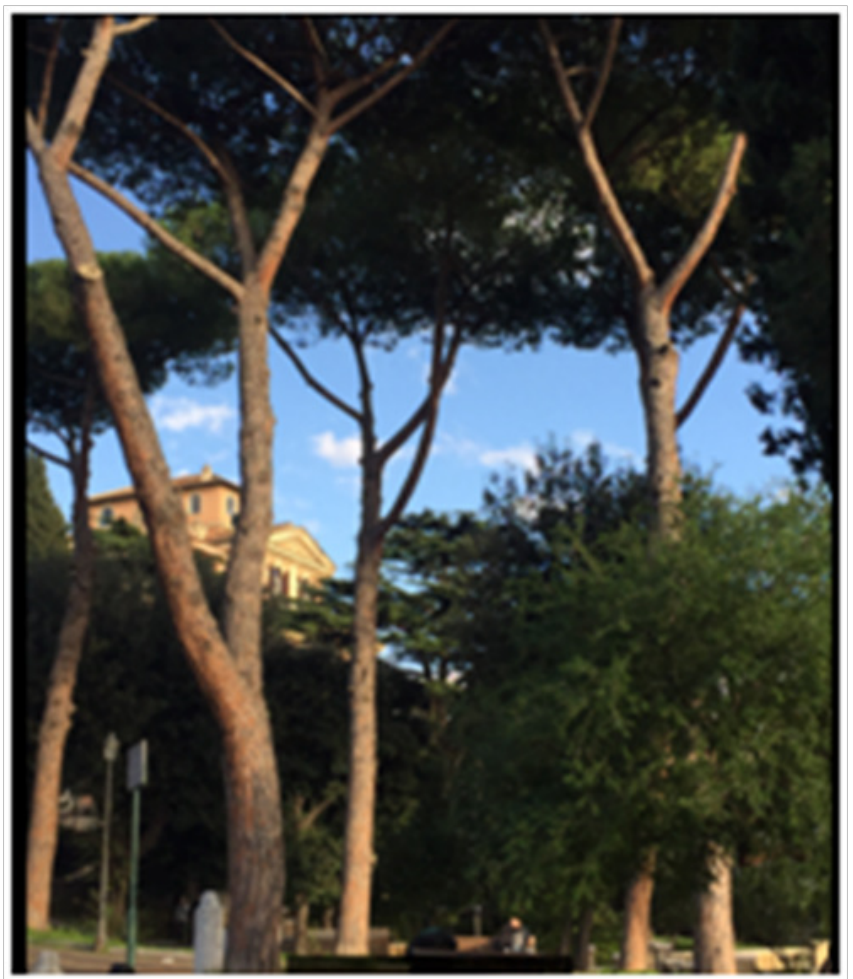

Figure $\mathbf{2}$ Melanin has the same function in plants, but in them, found primarily in the trunk. 


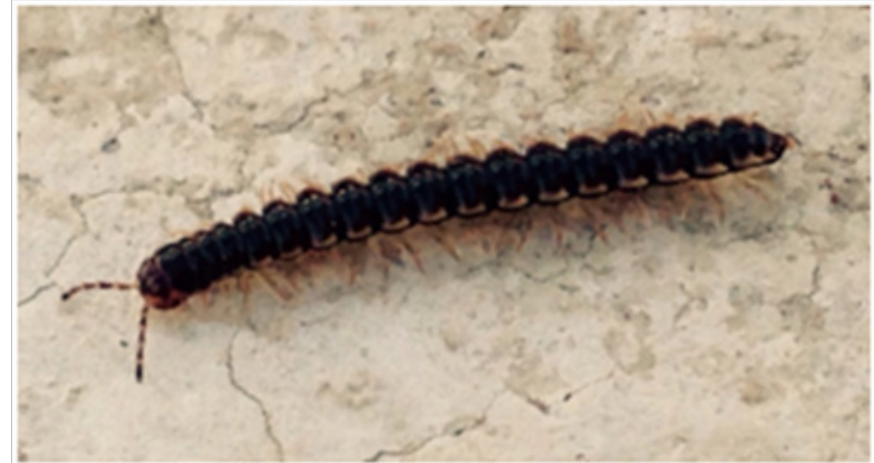

Figure 3 The dark colour characteristic of melanin, we can see it with the naked eye in almost all living things

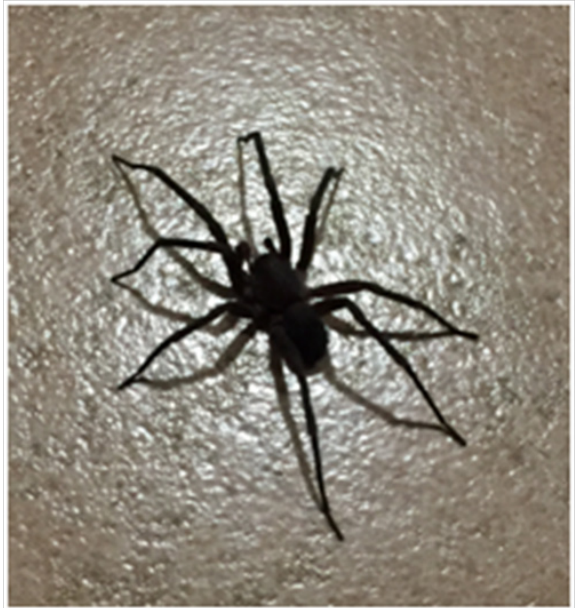

Figure 4 Wherever that the function of melanin is, is the same transforming the visible and invisible, light into chemical energy by the water molecule dissociation.

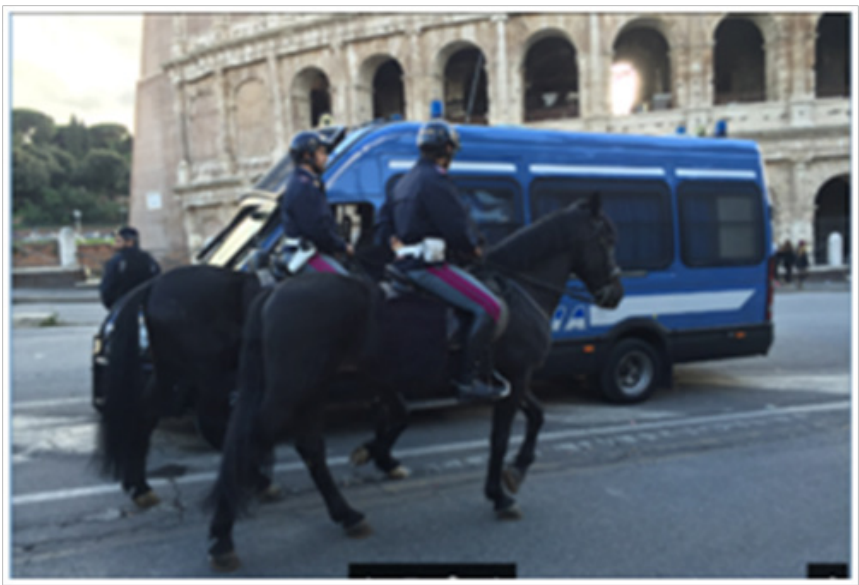

Figure $\mathbf{5}$ In mammals can be seen melanin mainly in the skin, since it tends to be close to the sources of energy, in this case the light of the Sun.

\section{The anatomical pattern of the eye of vertebrates in $\mathbf{G}$}

From the simplest to the most complex eyes (Figure 1), the presence of melanin pigment is the rule, and invariably the pigment is always melanin, which indicates early evolution, conservation and functional importance. The hagfish eye lacks lens, the motor cranial nerves III,
IV, and VI, there extraocular muscles are absent, and in certain species even vitreous body also is absent. The hagfish has skull but no vertebral column. The hagfish "eye" and retina are very simple, and resemble the pineal organ of vertebrates. In the Eptatretidae, the eyes ranging between 0.8 and $1.5 \mathrm{~mm}$ in diameter. The eye is situated immediately beneath an unpigmented patch of skin which stands out distinctly against the surrounding pigmented skin. The retina of hagfishes should have the capability to react on light stimulation, thereby there is an energy interchange; and the explanation is the melanin pigment, that transduces light into chemical energy dissociating water molecule and thereafter there is chemical energy available to impel the consequent detectable reactions. The epithelial cells in hagfishes, regardless of spices, do not contain pigment granules; thereby the pigment is in choroidal layer. The apical region of the inner segment is characterized by an aggregation of mitochondria, but mitochondria are not source of energy, instead it is a temperature regulator. Myxine glutinosa's retina contains between 150 and 180 ganglion cells, and about 800 and 1400 nerve fibers.

It is interesting that, during lamprey metamorphosis, the eye developed from a simple hagfish-like form to a vertebrate-like adult. The eye of adult lamprey is remarkably like our own, and it possesses numerous features, including the expression of opsins genes; that are very like those of the eyes of jawed vertebrates. The lamprey's cameralike eye has a lens, an iris and 5 extra ocular muscles; although it lacks intra-ocular muscles. Lamprey's retina has a structure very like that retinas of other vertebrates, with three nuclear layers comprised of the cell bodies of photoreceptors and bipolar, horizontal, amacrine and ganglion cells. ${ }^{23}$ The eye, in the adult Lampreys is a well-developed organ, with mono-layer of pigment epithelium. The outer segments of both long and short receptors have the double membrane discs enclosed by the cell membrane makes enfolding between the discs. These enfolding are as deep and wide as the individual discs of the outer membrane. The rod-like of the outer segments is also indicated by the occurrence of membranous inclusions in the pigment epithelium. ${ }^{24}$ The epithelial cells of Lampreys do not differ exceptionally from those of gnathostomas, and the amount of pigment granules is relatively small, compared with many other species having a dense pigmentation. Water is a dense medium compared with air, and pressure in the sea rises one atmosphere for each $10-\mathrm{m}$ depth, so that dep-sea animals are commonly exposed to pressures of some hundreds of atmospheres. However, the eye's pattern is very similar in both mediums. All life in the oceans and earth are ultimately dependent on light, and the eye is no exception. The eye requires energy from light not only to sight, also requires the chemical energy that results from melanin's water dissociation to impel the basic functions of the cell.

Water is much less transparent to visible light than is air and its spectral absorbance differs markedly. Short and long waves are rapidly attenuate with deep, leaving only the blue-green light which penetrates to deeper levels. ${ }^{25}$ Thereby, it seems paradoxical life in ocean depth, with so scarce light, but melanin can absorb any kind of energy, i.e. pressure; not only the full electromagnetic spectrum; dissipating it in the same way as makes with light: dissociating the water molecule and thereby generating chemical energy production. The so-called euphotic zone is distributed through about $100 \mathrm{~m}$ of surface water, but depth of euphotic zone varies with latitude and season. In these shallow waters, the rods and cones are familiar throughout the vertebrates. Deep-sea fishes, with few exceptions, lack cones. Their rods show features that do not occur commonly in shallow living fishes. Rods in general have an outer segment that contains the visual pigment, i.e. rhodopsin; an inner segment of which 
the scleral portion is composed largely of mitochondria and called the ellipsoid, and a more vitread portion called the myoid. The myoid extends from the ellipsoid to the outer limiting membrane. The rod nucleus is usually situated vitread to the outer limiting membrane in the outer nuclear layer. The outer segments in deep-sea fishes often account for mote of the retinal thickness than they do in shallow living fishes. This preponderance may be due to small rods present in large numbers and closely packed, or to long outer segments. So far, the visual pigment (rhodopsin) was considered the essential first link in the chain of events of photoreception; however, the finding of the unsuspected intrinsic property of melanin to transform visible and invisible light into chemical energy, as chlorophyll in plants, breaks the ground. The very first step in photoreception takes places in melanin, and thanks to the energy released by it in form of molecular hydrogen $\left(\mathrm{H}_{2}\right)$ and high energy electrons (e-), the conformational modification of visual pigments occur (Figure 6). Therefore, the first step in the retina's light response is at the level of melanin, mainly at pigmented epithelium layer, where the energy that is released is in the form of molecular hydrogen and high-energy electrons. Once the energy chemical released reaches the photoreceptors, then, and only until then, the visual pigments experience the conformational variations that give origin to the feeling of the visual sensation. Conformational variation of Visual pigments, e.g. rhodopsin; It is not the beginning, at the molecular level; of the highly complex biochemical processes that finally gives origin to an image at the level of consciousness; only is a small part of the entire processes, but its starts (energy of activation) with the energy chemical that comes of the dissociation of the molecule of the water, from the melanin that, for the eye, is in enough amount in the pigmented epithelium. In other words: without presence of the chemical energy from melanin, in form of $\mathrm{H}_{2}$ and high energy electrons (e-), the conformational variations of rhodopsin, should not happen (all cis-all trans) at all or at least not in accurate form.

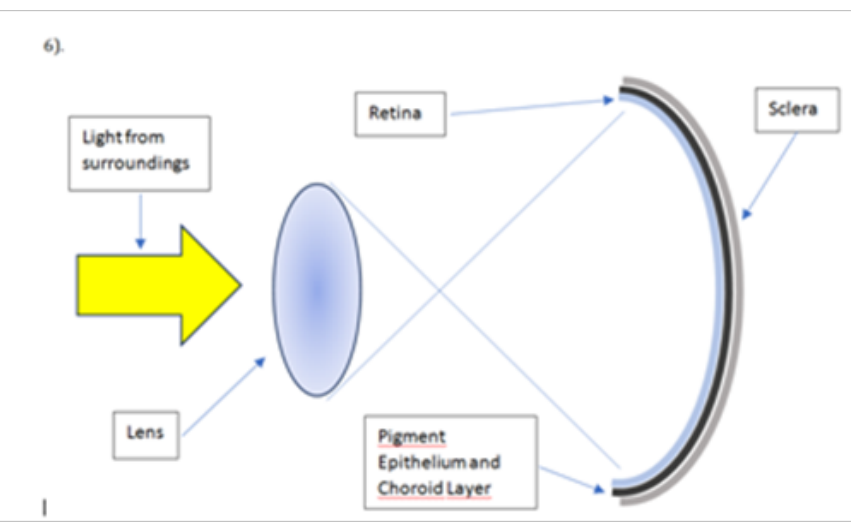

Figure $\mathbf{6}$ The function of the transparent elements of the eye, as cornea, crystalline (lens) and vitreous, not only is focus the rays of light so is form a recognizable image, which is inverted; on the retina, very close to the plane of the photoreceptors, but also concentrate the light so that the melanin present in the pigmented epithelium and the choroid, transform it into chemical energy by the dissociation of the molecule of water, such as chlorophyll in plants.

A proof of this concept, it's that, if for some reason, melanin in the pigment epithelium is damaged, for instance: trauma, infection, toxic compounds; etc., the function of receptors is comprised and may not give rise to the formation of images. The time that takes the melanin to dissociate the water molecule, releasing the energy and reach the photoreceptors, is in the range of the Nano and picoseconds. Hence the general pattern of any organ that can be considered as an eye both in vertebrates as invertebrates, is characterized, besides sclera, cornea, lens, retina, and vitreous; by the ever-presence of the melanin mainly in choroidal layer, as of another way, the energy that the different types of photoreceptors for carry to out its function requires, cannot be generated. The current dogma about the energy that requires any tissue, including the retina; for its function, its transported through the blood vessels in form of glucose; breaks into a thousand pieces when we find terrestrial or aquatic species whose retina has no blood vessels at all. There are no elaborated structures to increase metabolic nourishment through increased circulation ${ }^{26}$ along different species. Lizards have a papillary's conus, and snakes have a vasculosa retina for greater efficiency, but the retina of the turtle is avascular; it is nourished only by the choroid layer, and the nourishment is indirect through diffusion. The choroid layer (pigmented) handled $65 \%$ of the total blood that enters the eye, about $120-200 \mathrm{ml}$ per minute in man (Figure7); while the central retina artery only handles the $2 \%$. The single layer of photoreceptors (cones and rods) requires almost 10times more energy that it brain cortex, 6times more than the muscle heart and three times more than it renal cortex. And even in man, the layer of cones and rods is completely non-vascularized under normal conditions.

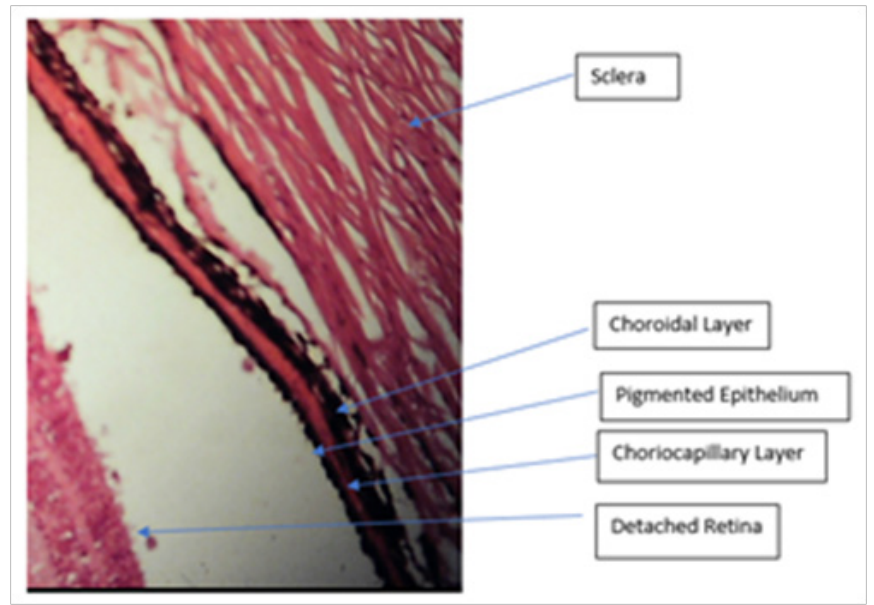

Figure 7 Histological section of the human choroid, where it can see the significant amount of melanin and the choroidal blood vessels. The layer of the choroid capillaries is so vascularized, that it seems as a red band bounded on both sides by melanin.

\section{The organization of the retina}

The way in which the rods and the cones respond to the light stimulus, must be rethink based energy that nourishes them, that comes from the melanin, and not of the blood vessels. Which explains why it has species that do not have blood vessels throughout the retina, and in the case of the man, the non-vascularized area is limited specifically to the layer of cones and rods (Figure 8). The lack of blood vessels of the layer of photoreceptors, whose energy requirements are the highest of the organism, it is astonishing. This situation, despite being paradoxical, sufficient attention had not been given, or had not be tried to explain otherwise. Perhaps there was hope that, eventually decipher the metabolism of tissues, the answer would appear. And it was, but it is clear that the energy of the photoreceptor is not from glucose carrying vessels, but a molecule that traditionally had been relegated by its apparent stability: melanin. The light coming from the outside, passes through the pupil, passing through the cornea, the lens and the vitreous; and it can reach the retina (Figure 9), where tiny granules of melanin in the perikarion of the cells begin to dissociate 
the water molecule, generating chemical energy, which is transported by the molecular hydrogen $\left(\mathrm{H}_{2}\right)$, which is the main carrier of energy in the entire universe. What could call the first phase, is observed in the electroretinogram as a-wave, and is the sum of the activity of the granules of melanin contained in the photoreceptors, bipolar cells; as well as in the cells of Mueller. B-wave is generated by the chemical energy that releases melanin located in the pigmented retinal epithelium and choroid layer; which is substantially greater than that contained in the retinal tissue, hence its size is significantly greater (Figure 9).

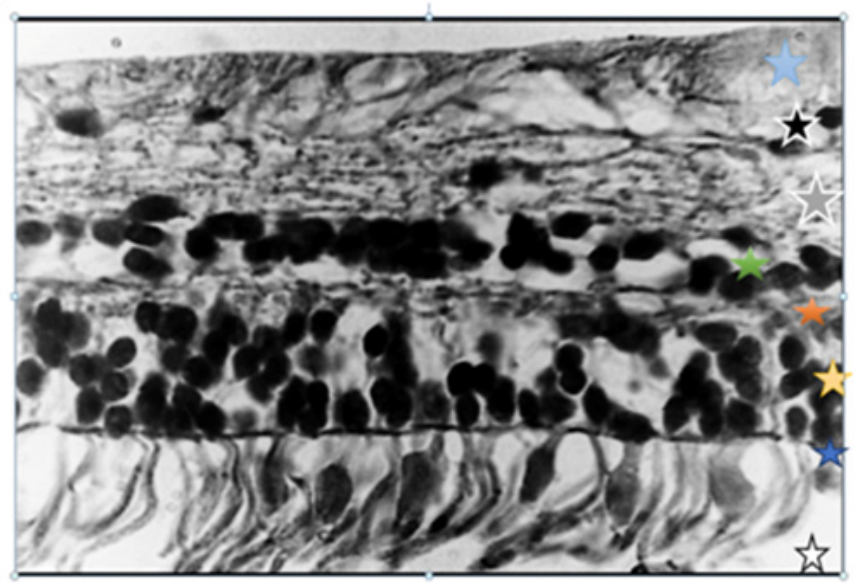

Figure 8 Microphotography of human retina, that shows rods and cones layer (white star), with some cell nucleus, which are normal after $40 y e a r s$ old. Outer limiting membrane (blue star). The nucleus of the rods and cones cells are in outer nuclear layer (yellow star). Outer plexiform layer (red star). Inner nuclear layer (Green star). Inner plexiform layer (gray star). Ganglion cells layer (black star), and finally the axis cylinders layer (pale-blue star).

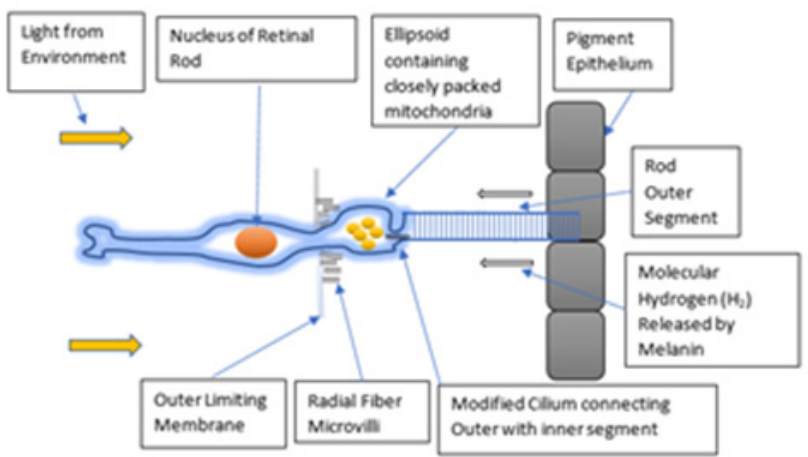

Figure 9 Diagram of the generation and distribution of energy comes from melanin. In accordance with our experimental results, mitochondria functions are mainly as temperature and phosphate level regulator, but not as energy source.

The ascending slope from the a-wave to the peak of the b-wave usually shows several small oscillations; these are called the oscillatory potentials (OPs); and reveal the function of amacrine cells. However, amacrine cells function also requires chemical energy available; and congruously, the OPs are elicited by light. In other words, when light reach melanin granules in retinal cells, an electrical response appears and can be detected by ERG (Figure 10). The b-wave size it is probably generated by the energy that comes from melanin in the pigmented epithelium and choroidal layer; where the amount of melanin is greater. The ERG measures can vary greatly, i.e. stimulus duration and intensity, electrode resistance and type; and the length of dark adaptation can all induce substantial changes in the recorded potential. Striking that no one had noticed that duration and intensity of the light stimulus affects in a significant way the extent of the ERG, much less had tried to explain it.; and even less that had relationship with melanin. ERG measures the response of retina to light; so, the pupil should be maximally dilated every time an electroretinogram is performed. A meiotic pupil can reduce the potential. Systemic blood pressure and local blood flow can affect ERG amplitude. Interestingly, diabetic patients frequently have low ERG amplitude, which is paradoxical if we are thinking that glucose is source of energy to retina, and thereby, ERG amplitude should be maximal. Anesthetics may also affect the amplitude of the b-wave, which remained unexplained until now; but the generation and distribution of energy from of melanin it explains, being a surprisingly exact process, the changes that the anesthetics agents induce in chemical-physical properties of the water, hampering the transformation of visible and invisible light into chemical energy by means of the dissociation of the molecule of the water is impaired in significant form, by which, the functional capabilities of the body also are affected which explains that, as a result of the administration of anesthetic agents, patients are gradually losing capability of movement, thought, until they finally fall into unconsciousness.

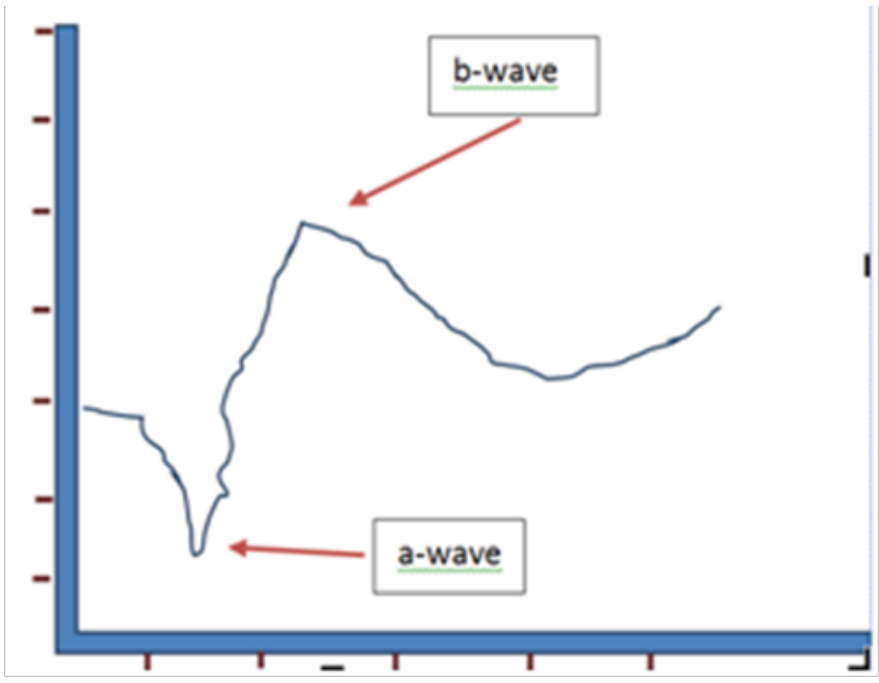

Figure 10 Diagram of normal ERG trace.

\section{The macula and the melanin}

To study the eye, one must take the organ apart and examine its components. To understand the vision, one must put the pieces back together. The hallmarks of life are properties, not of individual molecules but of large organized ensembles; each is a dynamic pattern deployed in space and time on a scale orders of magnitude above the molecular. The eye has everything to oxidize: abundant molecular $\left(\mathrm{O}_{2}\right)$ oxygen, lipids, floods light, as well as a very high metabolism; However, it is not the case. The explanation is that molecular hydrogen $\left(\mathrm{H}_{2}\right)$ that melanin releases because of the dissociation of the water molecule, is considered the best antioxidant that is known, because it can reduce oxygen, forming water. Liver Peroxidation occurring in rats by adjuvant-induced liver disease is antagonized by the melanin. It is likely that the melanosomes of the retinal pigmented epithelium provide the energy necessary to degrade the membranous disks of photoreceptors. 


\section{Differences in some other structures}

The turtle eye is small compared to birds and primates. The cornea is thick and shows little change in curvature in the limbos region of the sclera junction. Birds show a sulcus here to a greater degree. In the corneal epithelium, are the sclera ossicles (bony speckles), thin plates that overlap. There are varying numbers of plates, depending on species. Their value lies in the processes of accommodation, where they act to stiffen the sclera-corneal sulcus, which otherwise would be invaginate by intraocular pressure during the process. ${ }^{27}$ The pupil is round and fairly small in most species (Figure 11-13). The drug pilocarpine dilates a little, the pupil of the freshwater turtle Pseudonyms, but atropine has no effect. The lens is unusually soft in turtles. Freshwater turtles have a flatter lens those sea turtles. The sea turtle lens must carry the entire accommodative burden, since the benefit of any corneal refraction would be cancelled largely by immersion in sea water. Chelonia mydas, the green turtle; is emmetropic in water but extremely myopic in air. ${ }^{28}$ The freshwater Clemmys insculpta accommodates well in both media. In several freshwater species, the irises are beautifully colored: browns, reds, yellows, and greens. Retina turtle are avascular, as they are in most reptiles. There is an embryologic attempt at glial conus on the optic disc in some species, nut none lasts to adulthood. The absence of nonvisual structures is advantageous in avoiding interferences in light perception, but absence of direct blood circulation sets limit on metabolic utilization, where nutrients must diffuse (theoretically) over appreciable distances. The lizards which are visually dominated solve this problem by a conus papillarus, a vascularized structure that later evolved into the pectin of birds.

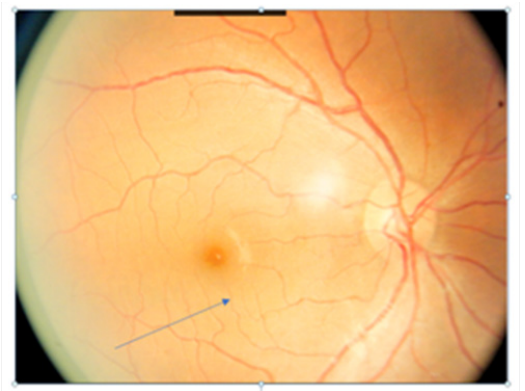

Figure II The macula (arrow), it named by Leonardo da Vinci, it is the area of maximum visual resolution, and coincidentally, also the greater concentration of melanin. The picture shows the normal fundus of the eye of a patient with photo-type IV in the Fitzpatrick classification.

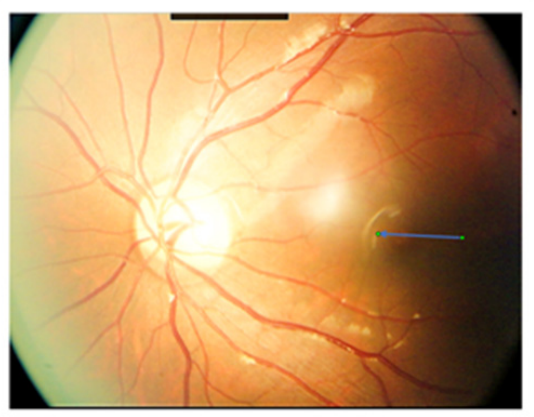

Figure I 2 Function macular depends on the energy that emanates from the melanin. When melanin is damaged for any reason (toxic agents, drugs, shock, intense lights, etc.) the amount of melanin tends to decrease and is reflected in the decrease in central vision. In photography, the macula is paler at the top (arrow), as if he were lost color and it is like what happens in patients with the disease of Alzheimer, Parkinson, of Huntington; in which, characteristically, the substantia nigra and locus coeruleus progressively lose its normal content of melanin.

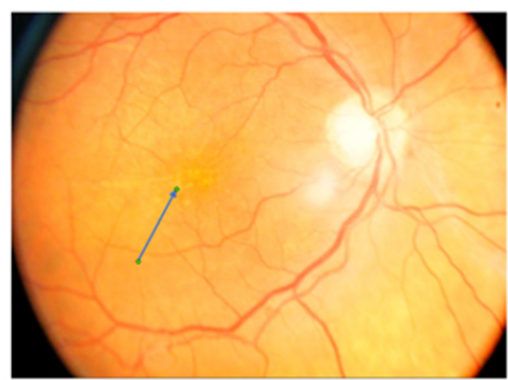

Figure 13 The amount of melanin in the fundus of the eye, and above all in the macula, is homogeneous normally, but in patients with age-related degeneration macular (ARMD), one of the first signs is the progressive loss of this homogeneity (arrow), produced by the deterioration and progressive loss of melanin.

\section{The avian pectin oculi}

It takes a whole cell to turn nutrients and energy into biological building blocks, to persist over time, to reproduce develops and evolves. When they become part of a cellular system, molecules operate under "social" control; reactions come to have location, direction, timing and function. The homogeneity which we observe in all living beings is astonishing, as they share the same molecular components: DNA, RNA, ATP, ADP, glucose, mitochondria, nucleus, endoplasmic reticulum, cell membrane, etc. And of course, melanin. If we ask from where comes this amazing regularity, to date we have no response, except if we consider the amazing regularity with which energy emanates from the melanin. ${ }^{29}$

The morphological pattern of the eye is a palpable sign of astonishing regularity. All eyes, from the simplest to the most complicated, have similar components, some vary in greater or lesser degree, as the rods, but it invariably is the presence of melanin, and as matter of fact, we then describe the eye of the bird, with its star component: the pectin, which, by the way; It has a large amount of melanin. Most birds fly, and have unique anatomical features confronting gravity. Bird hearts and pectoral are large, relatively 2 to 6times heavier than in man. Lungs differ substantially from those of mammals and vision benefits from relatively large eyes and keen acuity. ${ }^{30}$ It is paradoxical that most of anatomy peculiar to birds is well understood, with one exception: the pectin, an intra-ocular organ, heavy melanized; particularly developed in long-distance flyers (Figure 14), it is believed that protect the blood vessels against damage from UV light; and gives additional nourishment to the retina. Embryologically, the pectin arises as an ectodermal (glial) process from the edges of the optic fissure. The ectodermal elements are largely replaced later in development by an extensive invasion of mesodermal vascular tissue. In most birds, the pectin is largely completed at hatching, although in some species, full pigmentation may be delayed for some time. ${ }^{31}$ In 2008 Goodman \& Bercovich $^{32}$ proposed an interesting hypothesis: "does this melanized organ directly convert light energy for metabolic use?"

The pectinial base in chickens attaches to the inner nerve layer of retina, on optic nerve area (Figure 15-17). There are three to thirty pleats, depending species. ${ }^{33}$ In pectin's capillary endothelial cells, specialized membrane surfaces which with the pleats and intracellular vesicles have long suggested pectinial nutrition of the avascular avian retina, and an oxygen gradient from pectin to retina. ${ }^{34}$ The higher content of carbonic anhydrase and alkaline phosphatase indicates significant metabolic activity. ${ }^{35}$

Histological particularities of pectin remains unexplained, as absence of discernible endothelial cell boundaries, a clear cytoplasm, 
almost structure-less; and a thick, hyaline membrane surrounding capillaries. ${ }^{36}$ Except for the degenerated Kiwi's pectin, the pectin of all birds are folded or pleated. Histological features of the pectin's of all birds are remarkably similar. The pectin consists of a thin, pleated plexus of rather large capillaries held together by a sparse matrix of pigmented stroma cells. The pectin apex is held together by a densely-pigmented, fibrous bridge of tissue which has a reduced vascularization with respect to the pectin pleats. The absence of nervous tissue in pectin underscores the numerous sense-organ theories of pectin function. The pectin capillaries form an extensively anatomized network, ${ }^{37}$ like capillaries arrangement in choroidal layer in the eye's man. Enzymes as carbonic anhydrase, alkaline and acid phosphatases, and aminopeptidase have been found in large amounts in the pectin. It is interesting that the amount of enfolding of the apical and basal plasmalemmal of the capillary endothelium in both the pectin and the ciliary body increased greatly in both the pectin and the ciliary body after administration of acetazolamide. The alkaline phosphatase activity of pectin tissues changes markedly upon dark adaptation. ${ }^{38}$

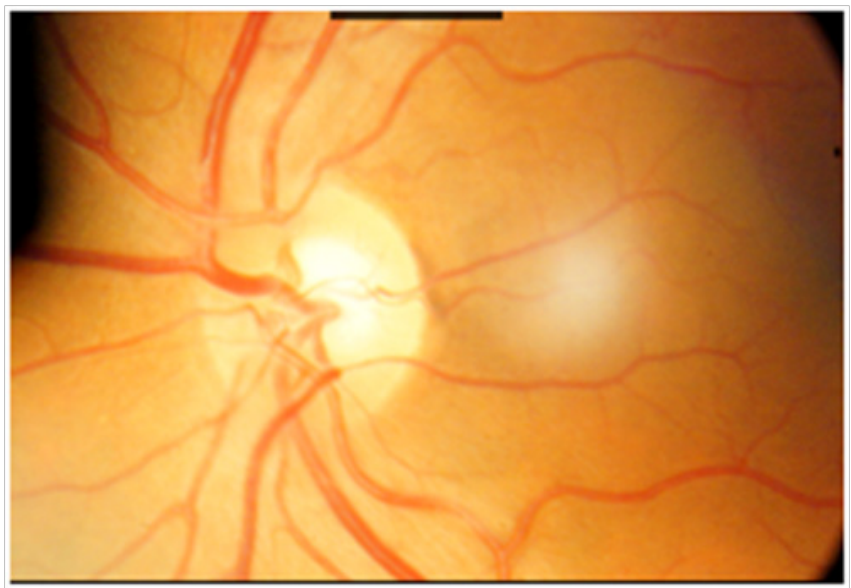

Figure 14 The observation that led to the final finding of the unsuspected property intrinsic of the melanin of dissociate it molecule of the water, using for this, the energy of the light visible e invisible; was the constant presence of the melanin (arrow) in the surroundings of the optic nerve.

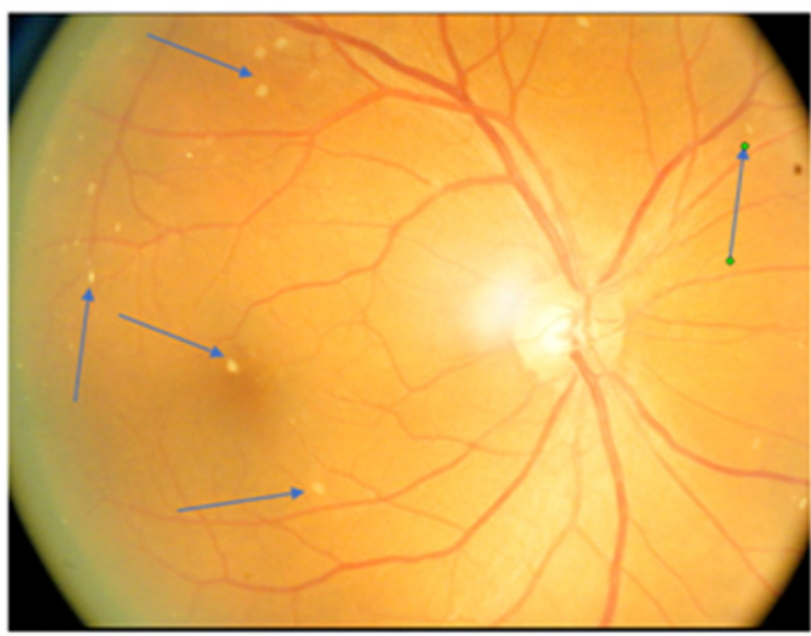

Figure I5 Melanin has a great affinity for calcium, about a 1000times more than bone. One of the usual signs, presenting patients with insufficient melanin energy distribution, and generation is that calcium has changes in their normal behavior and tends to build up, for example, in the vitreous body, like the one shown in this picture (arrows).

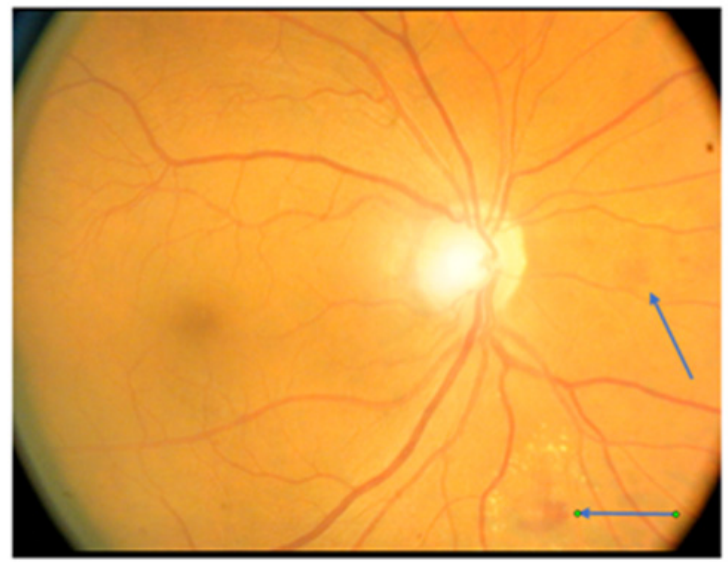

Figure 16 diabetic retinopathy can be interpreted as an imbalance between mass and energy. When chemical energy levels from melanin are not adequate, the body cannot do what it does very well, since millions of years, has done millions of times. For example, the body has handled glucose from the beginning of time. Some of typical lesions of diabetes on retina are shown in photography (arrows).

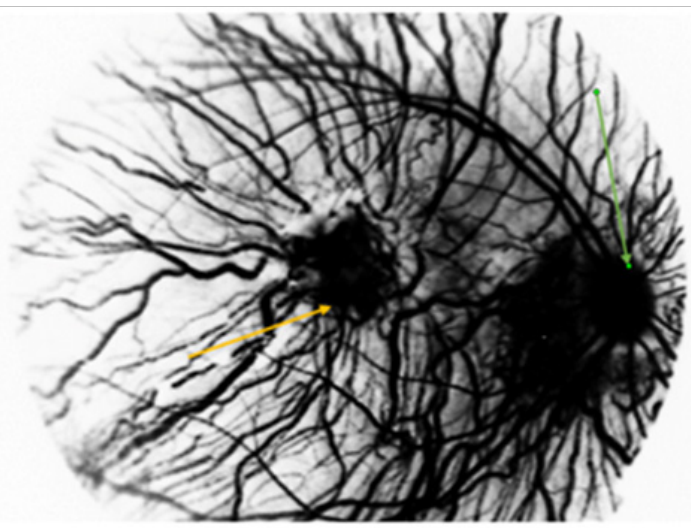

Figure 17 Photograph taken with 850nm wavelength, showing choroidal and retinal circulation overlapped. In macular area (center) is observed a greatest blood vessel number. The optic nerve is seen at right of photography (Green arrow), and macular zone (yellow arrow) at center.

Capillaries have been regarded as main pectinial tissue over decades. It is said that melanocytes to support the pectinial vascular mass in shape and function within the vitreous. ${ }^{39}$ However, opposite is not less true. Besides to numerous tightly packed pigment granules, that obscuring the melanocytes cytoplasm, there can be typically two to four nuclei with non-discernible limiting membranes in pectinial melanocytes. Melanocytes cell membrane adjacent to the vitreous is very thin. A direct interaction between pectinial capillaries and melanocytes is improbable. The Golgi complex in the melanocytes seems as developed as in the endothelial cells. Each melanocyte can have several Golgi bodies containing compact groups of stacked parallel lamellae with vesicles close bye, and mitochondria with each pigment granule. Guinea pigs and rabbits are without vascularized retina, but they have no pectin, perhaps due to the eye is smaller.

Theories about pectin function are numerous, around 30 or 40 ; including that melanin absorbs excess of light reducing distortions to vision and motion perception (Figure 18) and, diminishing damage to retina and to pectinial capillaries. It has been hypothesized that the seat of the avian magnetic sense is precisely the pectin. The dark pigmentation (melanin) and velvety texture of the pectin surface, especially on the bridge, indicate that pectin absorbs light, analogous 
to the light baffles found in many cameras. However, the hypothesis that pectin replaces the missing central retinal artery system in the avian eye, means that pectin oculi of birds is a nutritive organ supplying the inner layer of retina (close vitreous body) with oxygen or more precisely with molecular hydrogen $\left(\mathrm{H}_{2}\right)$. The cauterization of the retro bulbar supplying arteries of the pectin in the domestic pigeon, produce a rapid, irreversible degeneration of the inner retinal layers. Wingstrand \& Munk ${ }^{40}$ made a small number of intraocular measurements of virtual oxygen tension before and after pectin ablation, which demonstrated that an oxygen gradient from the pectin to the retina had been destroyed. A relative anoxia in the vitreous humor following pectin ablation was advanced as the probable cause of retinal atrophy. However, the main product of water dissociation is molecular hydrogen $\left(\mathrm{H}_{2}\right)$ since is the main energy carrier in nature and universe, thereby, when pectin is destroyed, the transformation of light into chemical energy through water dissociation is impaired significantly, thereby, the inner layers of retina cannot maintain neither function nor form. When the sensing electrode was pushed against or slightly into the retina, the oxygen tension was always three to four higher than at vitreous-retina boundary. The source of detectable oxygen is the melanized tissue so-called choroidal layer. Thereby the pectin function is transform light, visible and invisible; into chemical energy through dissociation of water molecule.

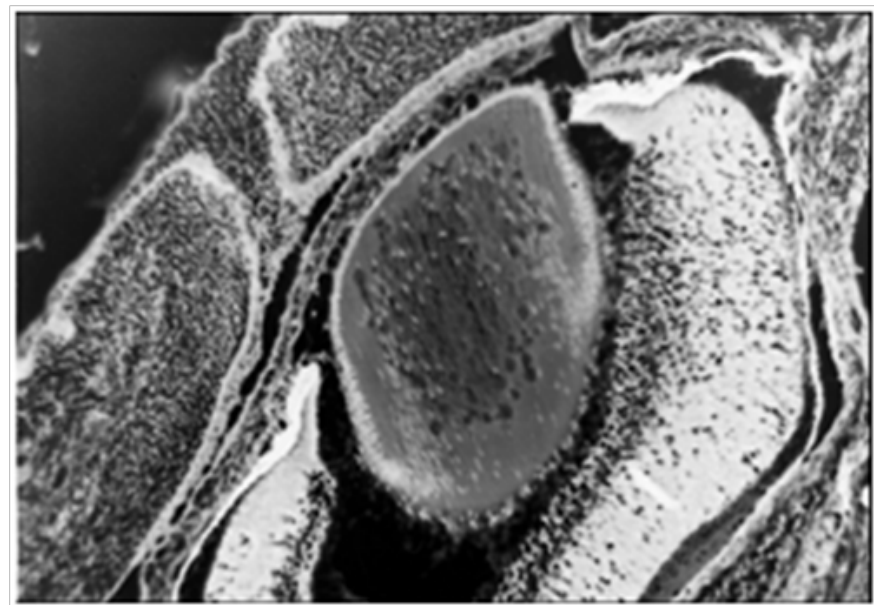

Figure 18 Histologically section of the eye of an embryo of mouse, in which is observed the formation and growth of the different eye-structures (cornea, crystalline, retina, vitreous) and extra-oculars (eyelids). Despite being at a relatively advanced stage of embryogenesis, the presence of blood vessels is very scarce.

It could say that the melanin of the pectin, facilitates the search for solar energy by birds, and simply follow the direction in which the Sun's energy is highest. The pectin is extraordinarily rich in carbonic anhydrase, due to facilitates greatly the drive of the $\mathrm{CO}_{2}$, keeping it in adequate levels for the tissue. It is wrongly believed that a significant portion of retinal ATP is generated by oxidative phosphorylation, however, glucose is not a source of energy, instead is only a source of biomass. With glucose, the organisms build up the biomolecules needed to continuous replenishment; but the energy required, is taken from light through the dissociation of the water molecule. This chemical energy is transported by molecular hydrogen and high energy electrons. Oxygen is toxic at any concentration. The low levels of bound succinic acid dehydrogenase over much of the retina of the domestic pigeon, suggest that mitochondria are substantively reduced or possibly absent. ${ }^{41}$ Blood vessels of the pectin are grossly permeable to a variety of dyes, especially fluorescein, such as choroidal eye layer in humans. The aqueous humor is secreted in vertebrate eyes, by ciliary processes. The aqueous humor is thereafter secreted into the posterior chamber of the eye; from there it flows around the lens through the pupil into the anterior chamber where it is drained into the venous circulation at the edge of Schlemm channel. However, aqueous humor flows through the outflow network at an extremely low flow rate $(2.0 \mu \mathrm{l} / \mathrm{min}$, producing (theoretically) a surprisingly large pressure drop over a short distance (less than $1 \mathrm{~mm}$ ) of Schlemm Channel. Melanin of uveal tract and pectin, can dissociate and reform the water molecule, thereby aqueous humor is re-absorbed by the same tissues that secrete it mainly. It is already known that pectin has a fluid secretion.

The pectin is smaller young birds and growth during development. The Red-wing (blackbird) pectin showed few pleats and the English sparrow only three, though 20 were present in the adult. ${ }^{42}$ Recovery from acute hypoxia without detectable oxygen repayment in 16-daysold chicken embryos in the dark, suggested anaerobic pathways are minor in their energy budge $t^{43}$ however, if we take in account that melanin absorbs visible and invisible light, then biochemical explanation is different. The greater part of energy budget comes from light, and not from food. Thereby oxygen is not necessary to be combined with glucose to get energy. This concept resolves the mystery about normal development of avian embryos at very low tissue oxygen pressure in some species, which so was considered to involve cellular and biochemical characteristics promoting oxygen utilization. ${ }^{44}$ Therefore, oxygen consumption by birds is practically non-existent. A clue that energy production by melanin is important (Figure 19 \& 20). Strikingly, since 1992, Tadeus Sarna published that RPE-choroid layer contains the highest intracellular concentration of oxygen in the entire body. However, no explanation was given.
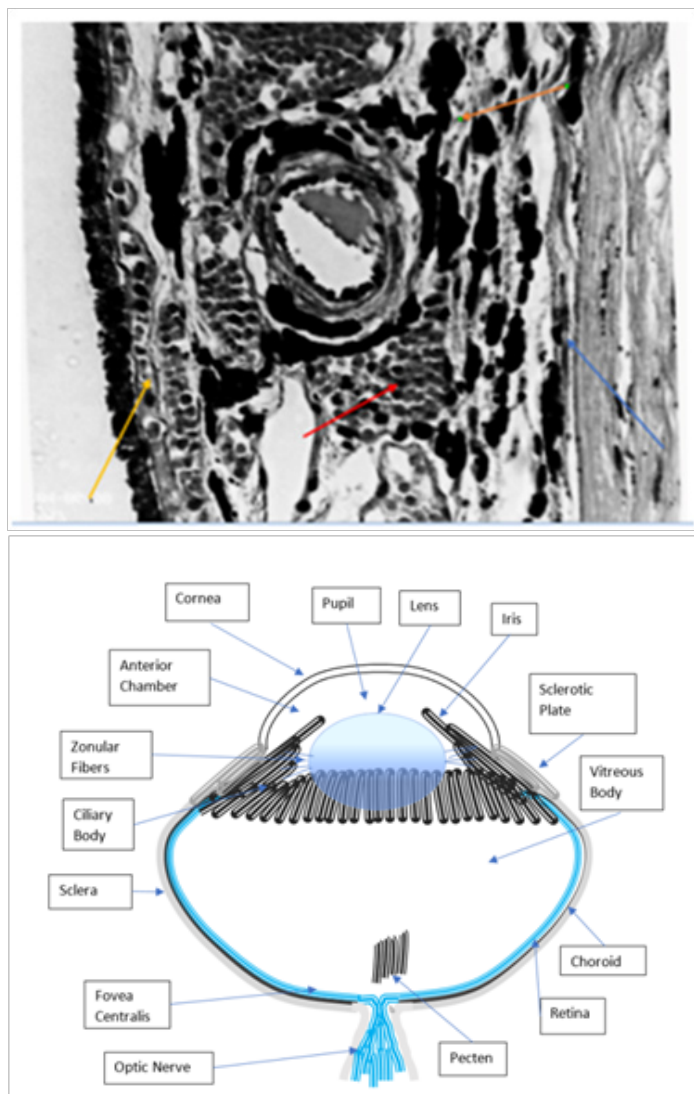

Figure I 9 Diagram of bird's eye, showing the pecten, that projecting freely in the vitreous body. The pecten varies in shape and size by species. 

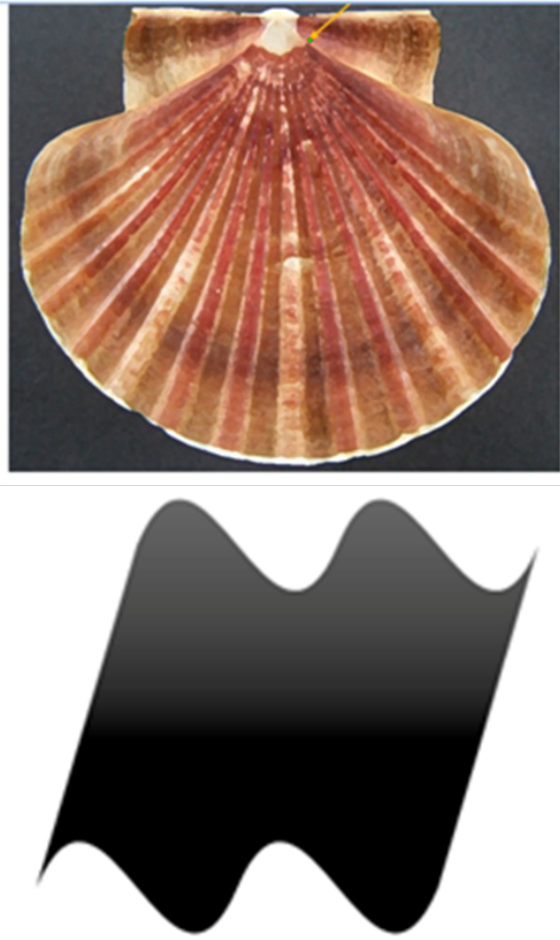

Figure 20 Drawings of the pectin, a structure which starts in the optic nerve (Yellow arrow); its resemblance with a shell is substantive.

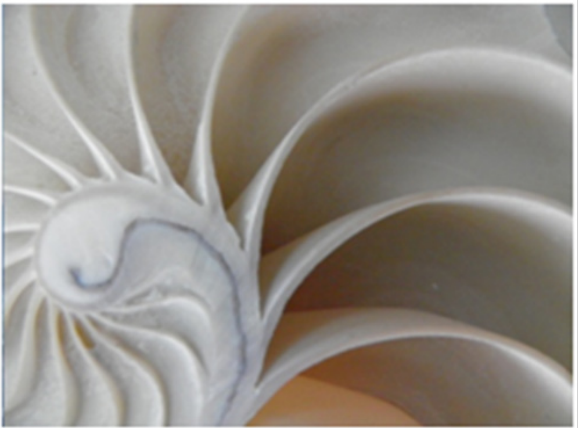

Figure 2I The typical pecten gross appearance is suggestive of a steam radiator. In the photography is observed the inside of a shell of snail, which has several similarities with the anatomical arrangement of pecten of the birds.

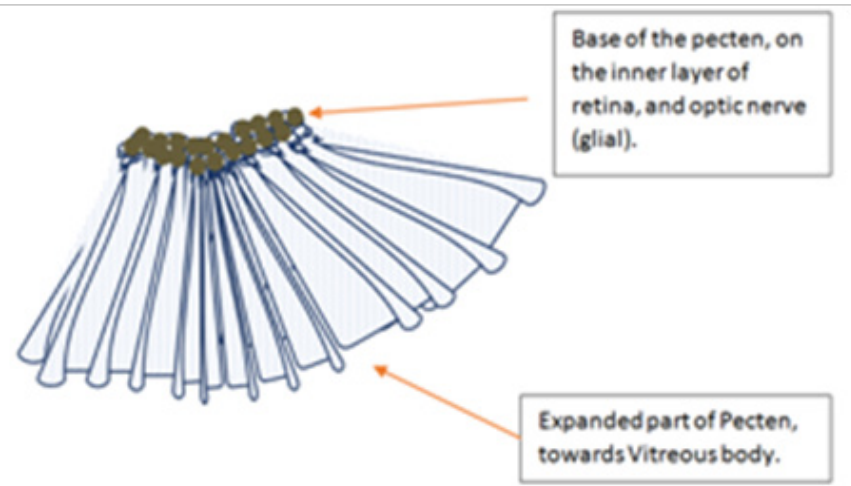

Figure 22 Diagram of Pecten arrangement in the bird's eye. There is a remarkable variability of several external pecten features as amount of melanin, length, thickness, and number of pleats. Pecten seems ad pleated fan, or a pleated cone.

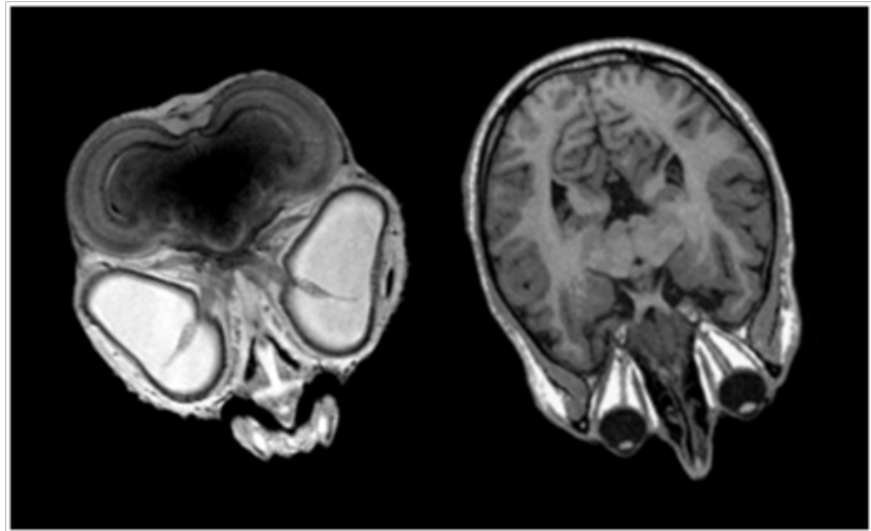

Figure 23 Magnetic resonance image (MRI) of bird's eye (left). Pecten arises where the optic nerve begins. Notice that bird's eyes fill completely orbital structure, thereby, there are not extraocular muscles. Oppositely, man's eyes are smaller, with well-developed extraocular muscles (right), and no pecten presence at all. Image source Common Creative License.

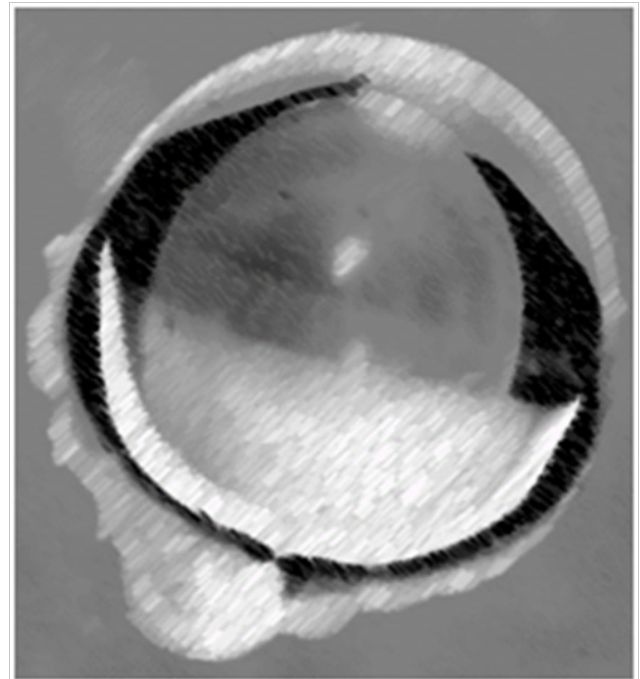

Figure 24 Drawing of an eye of a mouse, where we can appreciate the sheer size of the lens in proportion to the size of the eye, but the remarkable amount of melanin, obvious.

\section{Conclusion}

The biology of the eye in the animal Kingdom, must rethink challenging the concepts of metabolic pathways that depart from so-called energy which the body obtained by controlled combustion (oxidation) of glucose. Melanin takes part in all the chemical reactions that make up the biology of the eye, even since its formation, as at 35 days of gestation, the eyeball is completely melanized, providing energy requiring the complex processes of embryogenesis. Moreover, it is known that during the early stages, the eye, and specifically the choroid is a blood-forming organ. The general vertebrate plan of an eye-ball encased in three coats: sclera, choroid, and retina, forming a dark chamber filled with clear fluids under pressure. The cornea, a transparent tissue of varying refractive power, depending of habitat. Within the eye is a lens whose means of accommodation is variable in terms of evolution. The lens is pliable and transparent. Accommodation is obtained by striated ciliary muscles cantilevering from a ring of scleral ossicles to deform the lens, rather by to-and-fro movement as it is in fishes. For binocular vision, there is assistance in convergence by a transversalis muscle which orients the lens nasally. The mechanisms 
for both accommodation and convergence are newly evolved for reptiles. The photopigments have shown environmental distribution, but are conformed to the vitamin $\mathrm{A}_{1}$-vitamin $\mathrm{A}_{2}$. Creatures confined to land and in the sea shared a broad assignment to vitamin $\mathrm{A}_{1}$, or retinol pigments. The photopigments of freshwater animals have their peak absorbance shifted to longer wavelengths. These pigments in fishes are based on vitamin $\mathrm{A}_{2}$ or 3-dehydroretinol. These pigments were found in cone receptors identified by the geometry of the outer segments and by the presence of oil droplets, described by first time in 1843 . Krause, in 1863, supposed that there might be a universally photopigment critically placed, and this optically dense oil droplets acting as cut-off filters so as to permit only certain wavelengths to affect the outer segments. The yellow droplets contain zeaxanthin a $\beta$-carotene.

The similarity in the chemical compounds that is derived of it energy that emanates of the melanin, makes us to think that it melanin not only delivers energy, but carries information, something as well as a code binary, which are very frequent in the nature. The Anatomy of the retina varies from species to species, as even found structures that could classify is as shells; or cones that come in contact with other cones, rods, bipolar cells; and with the horizontal cells, influencing is each other reciprocally. The alignment of receptors is a virtue shared within vertebrates. It allows for increased efficiency of quintal absorption in the outer segments. There is general agreement about the electric responses of retinal neurons to light in vertebrates. Cones hyperpolarize during increases in membrane resistance. This light-elicited increase in membrane resistance has been attributed to a decrease in sodium conductance across the outer segment membrane. ${ }^{45}$ The peak hyperpolarization is governed by potassium ion concentration. A change of sodium ion concentration affects the potential of the plateau of the response, but it does not affect the peak of the response. ${ }^{46}$ The size of the photo-response is linearly related to the logarithm of the external sodium concentration. The outer segments of photoreceptors have a high permeability for sodium in the dark, a current flow is established that enters the photoreceptor at the outer segment and exits at the inner segment. With illumination, the current flow is shut off because of a decrease in sodium permeability, and the resultant membrane potential is determined largely by the concentration of potassium ions. Theoretically, absorption of photons results in a chain of chemical reactions whose end-product is an intermediary substance that interacts with the channels and affects their permeability. Theoretically this intermediate substance was calcium. Is of call it attention, that the researchers explored numerous molecules present in them photoreceptors and its immediate environment, but never turned to see to the melanin by what to the date not is had detected his unsuspected capacity as transducer of light in energy chemical, dissociating it molecule of the water.

The energy that constantly emanates from the melanin in the form of $\mathrm{H}_{2}$ and e- is evident both in the normal and the pathological processes. Changes in the retina and choroid are observed after the application of laser energy, be explained because the coherent light is absorbed by melanin and thereafter dissipated throughout the dissociation of water molecule, and on the other hand, monofilament of DNA are very effective to increase the synthesis of melanin in pigmented cell cultures; which could explain the activation of melanocytes eye after the tissue destruction by the laser. More melanin is expected a greater production of chemical energy, which explains that diabetic retinopathy, is less severe in people with dark skin compared to white-skinned people. A similar behavior is observed in age-related macular degeneration (ARMD), since it is the leading cause of blindness in people of fair-skin. The elaborate and efficient mechanisms for images registration, starts with the energy that comes from melanin. The information processing and coding taking place on the retinal structure are majorly dependent of the very first step: water dissociation by melanin.

The eye has everything to oxidize: abundant molecular $\left(\mathrm{O}_{2}\right)$ oxygen, lipids, flood light, as well as a very high metabolism; However, not the case. The explanation is that molecular hydrogen $\left(\mathrm{H}_{2}\right)$ that melanin releases because of the dissociation of the water molecule, is considered the best antioxidant that is known, because it can reduce oxygen, forming water. Liver Peroxidation occurring in rats by adjuvant-induced liver disease is antagonized by the melanin. It is likely that the melanosomes of the retinal pigmented epithelium provide the energy necessary to degrade the membranous disks of photoreceptors.

\section{Acknowledgements}

None.

\section{Conflict of interest}

The author declares no conflict of interest.

\section{References}

1. Darwin C. On the Origin of Species. 1859:186.

2. Conway Morris S. The Cambrian "explosion" slow-fuse or megatonnage? Proc Natl Acad Sci USA. 2000;97(9):4426-4429.

3. Gehring WJ. Historical perspective on the development and evolution of eyes and photoreceptors. Int J Dev Biol. 2004;48(8-9):707-717.

4. Berghammer AJ, Klinger M, Wimmer EA. Genetic techniques: A universal marker for transgenic insects. Nature. 1999;402(6760):370371.

5. Bellono N W, Escobar IE, Oancea E. A melanosomal two-pore sodium channel regulates pigmentation. Sci Rep. 2016;6:26570.

6. Bumsted KM, Barnstable CJ. Dorsal retinal pigment epithelium differentiate as neural retina in microphthalmia( $\mathrm{mi} / \mathrm{mi})$ mouse. Invest Ophthalmol Vis Sc. 2000;41(3):903-908.

7. Torczynski E. Choroid and suprachoroid. In: Ocular anatomy, embryology, and teratology. In: Jacobiec FA, editor. UK: Harper and Row; 1982. p. 553-585.

8. Ortonne JP. The effects of ultraviolet exposure on skin melanin pigmentation. J Int Med Res. 1990;18 (Suppl 3):8C-17C.

9. Berman ER. Biochemistry of the retinal pigment epithelium. In: The retinal pigment epithelium. In: Zinn KM, Marmor MF, editors. London: Harvard University Press; 1979. p. 83-102.

10. Noell WK. Possible mechanisms of photoreceptor damage by light in mammalian eyes. Vision Res. 1980;20(12):1163-1171.

11. Bok D, Young RW. Phagocytic properties of the retinal pigment epithelium. In: The Retinal pigment epithelium. In: Zinn KM, Marmor MF, editors. London: Harvard University Press; 1979. p. 148-174.

12. Marshall J. The aging retina: Physiology or pathology. Eye (Lond). 1987;1(pt 2):282-295.

13. Feeney L. Lipofuscin and melanin of human retinal pigment epithelium. Fluorescence, enzyme cytochemical and ultrastructural studies. Invest Ophthalmol Vis Sci. 1978;17(7):583-600.

14. Dorey C K, Torres K, Swart T. Evidence of melanogenesis in porcine retinal pigment epithelial cells in vitro. Exp Eye Res. 1990;50 (1):1-10. 
15. Sarna T. Properties and function of the ocular melanin-A photobiophysica view. J Photochem Photobiol B. 1992;12(3):215-258.

16. Glass $\mathrm{K}$, Ito $\mathrm{S}$, Wilby $\mathrm{PR}$, et al. Direct chemical evidence for eumelanin pigment from the Jurassic period. Proc Natl Acad Sci U S A 2012;109(26):10218-10223

17. Schraermeyer U. Localization of peroxidase activity in the retina and the retinal pigment epithelium of the Syrian golden hamster (Mesocricetw auratus). Comp Biochem Physiol B. 1992;103(1):139-145.

18. Szamier RB, Berson EL. Retinal ultrastructure in advanced retinitis pigmentosa. Invest Ophthal Vi Sci. 1977;16(10):947-962

19. Schraermeyer Ulrich. Does Melanin Turnover Occur in the Eyes of Adul Vertebrates? Pigment Cell. 1993;6(4 Pt 1):193-204

20. $\mathrm{Hu} \mathrm{F}$, Mah K. Changes in melanosomes with age in iridial stroma melanocytes of Rheslls Macaques. Mech Ageing Dev. 1983;23(1):95102

21. Takeda K, Takahashi N, Shibahara S. Neuroendocrine functions of melanaocyte beyond the skin-deep melanin maker. Tahaku J Exp Med 2007;211(3):201-221.

22. Tran ML, Powell BJ, Meredith P. Chemical and structural disorders in eumelanins: a possible explanation for broadband absorbance. Biophys J. 2006;90(3):743-752.

23. Panopoulou G, Poustka AJ. Timing and mechanism of ancient vertebrate genome duplications - the adventure of a hypothesis. Trends Genet 2005;21(10):559-567.

24. Ohman P. Fine structure of photoreceptors and associated neurons in the retina of Lampetrafluviatilis (Cyclostomi). Vision Res. 1976;16:659-662.

25. Jerlov NG. Optical studies of ocean water. Rept Swed Deep-Sea Exped 3 Physics Chern Fasc. 1951;1:1-59.

26. Crescitelli F, Dvorak CA, Eder AM Granda DJ, et al. Vision in Turtles, of the book The Visual System in Vertebrates. In: Frederick Crescitelli, editor. USA: Springer-Verlag Berlin; 1977. p. 451- 495.

27. Beer T Die. Akkomodation des Auges bei den Reptilien. Pfliigers Arch. 1898;69:507-568

28. Ehrenfeld DW, Koch AL. Visual accommodation in the green turtle. Science. 1967;155(3764):827-828

29. Wood CA. The fundus oculi of birds, especially as viewed by the ophthalmoscope a study in comparative anatomy and physiology. 1917.

30. Brooke ML, Hanley S, Laughlin SB. The scaling of eye size with body mass in birds. Proc R Soc Lon B. 1999;266:405-412.

31. Brach Vincent. The functional significance of the avian pecten: a review. The Condor. 1977;79:321-327.
32. Goodman G, Bercovich D. Melanin directly converts light for vertebrate metabolic use: Heuristic thoughts on birds, Icarus, and dark human skin. Medical Hypotheses. 2008;71:190-202.

33. Seaman RA. Starn HA. A correlated light and electron microscope study on the pecten oculi of the domestic fowl (Gallus domesticus). Exp Eye Res. 1963;2:163-172.

34. Pettigrew JD, Wallman J, Wildsoet CF. Saccadic oscillations facilitate ocular perfusion from the avian pecten. Nature. 1990;343(6256):362 363.

35. Bawa S, Yashroi R. Effects of light and dark adaptation on the retina and pecten of chickens. Exp Eye Res. 1972;13(1):92-97.

36. Kiama SG, Maina JN, Bhattacharjee J, et al. A scanning electron microscopy study of the luminal surface specializations in the blood vessels of the pecten in a diurnal bird, the black kite (Milvus migrans). Ann Anat. 1998;180(5):455-460.

37. Dieterich HJ, Rogenbauer KA, DIeterich CE. The blood vessel system of the pecten oculi in the House Sparrow (Passer domesticus): its arquitecture and fine structure studied by light, transmission and scanning electron microscopy. Cytobiology. 1976;13:57-73.

38. Bawa SR, YashRoy RC. Effect of the light and dark adaptation in the retina and pectin of the chicken. Exp Eye Res. 1972;13(1):92-97.

39. Brooke ML, Hanley S, lAughlin SB. The scaling of eye size with body mass in birds. Proc R Soc Lond B. 1999;266:405-412.

40. Wingstrand $\mathrm{KG}$, Munk $\mathrm{O}$. The pecten oculi of the pigeon with particular regard to its function. Biol Skr Danske VIden Selsk. 1965;14:1-64.

41. Hughes JT, Jerrome D, Krebs HA. Ultrastructure of the avian retina: an anatomical study of the retina of the domestic pigeon Columba liva, with particular reference to the distribution of mitochondria. Exp Eye Res. 1972;14(3):189-195.

42. Slonaker JR. The development of the eye and its accessory parts in the English Sparrow. J Morph. 1921;35(2):262-357.

43. Ar A, Girard H, Rodeau JL. Oxygen uptake and chorioallantoid blood flow changes during acute hypoxia and hyperoxia in the 16-day old chicken ambryo. Respir Physiol. 1991;83:295-312.

44. Leon-Velarde F, Moge CC. Avian embryos in hypoxic environments Respir Physiol Neurobiol. 2004;141:331-343.

45. Bortoff A, Norton AL. An electrical model of the vertebrate photoreceptor cell. Vision Res. 1967;7(3):252-263.

46. Cervetto L, Marchiafava P L, Pasino E. Influence of efferent retinal fibres on responsiveness of ganglion cells to light. Nature. 1976;260:56-57. 